\title{
CIÊNCIA'NATURA
}

\section{Determinação da fragilidade ambiental de uma bacia hidrográfica em relação à suinocultura utilizando SIG}

\section{Determination of environmental fragility of a watershed regarding to swine activity using GIS}

\author{
Fernanda Maria Follmann ${ }^{1}$, Júlia Caetano Manfio², Rafael Cabral Cruz', \\ Robson Evaldo Gehlen Bohrer ${ }^{3}$, Tadeu Luis Tiecher ${ }^{4}$ Thiago Boeno Patricio Luiz ${ }^{l}$ \\ ${ }^{1}$ Universidade Federal de Santa Maria, Campus de Santa Maria, Santa Maria, RS, Brasil. \\ ${ }^{2}$ Universidade Federal do Pampa, Campus de São Gabriel, São Gabriel, RS, Brasil \\ ${ }^{3}$ Universidade Estadual do Rio Grande do Sul - UERGS - Três Passos. RS, Brasill. \\ ${ }^{4}$ Instituto Federal Farroupilha, Campus Alegrete, Alegrete, RS, Brasil
}

\section{Resumo}

A intensificação da utilização dos recursos naturais teve início após a revolução industrial, aumentando a ocupação desordenada das bacias hidrográficas e a degradação do meio ambiente ao longo do último século. Os estudos de fragilidades ambientais auxiliam na identificação de áreas com maior ou menor fragilidade em relação a determinado aspecto ou atividade analisada, contribuindo para a tomada de decisão e adoção de estratégias para minimizar tais impactos. Assim, o objetivo do trabalho foi avaliar a fragilidade ambiental da Bacia Hidrográfica do Rio Lajeado Erval Novo frente à suinocultura, a fim de subsidiar o apoio à tomada decisão para o sistema de licenciamento ambiental. Para tanto, realizou-se uma avaliação ambiental integrada da bacia hidrográfica a partir do processamento de dados em Sistema de Informações Geográficas, utilizando um modelo baseado em variáveis quali-quantitativas e agregando caracteristicas socioambientais com o intuito de hierarquizar áreas com maior e menor fragilidade ambiental em relação aos efluentes suinos. As áreas a sudoeste e nordeste da bacia hidrográfica estudada foram diagnosticadas como os pontos de maior fragilidade ambiental. Esta fragilidade foi relacionada, principalmente, à maior geração de carga de efluentes suinos e aos condicionantes que contribuem para o processo de fragilização ambiental das áreas, como o uso e tipo de solo, declividade e proximidade aos recursos hídricos. $O$ mapeamento das fragilidades ambientais, por meio da abordagem das variáveis e condicionantes especificas das áreas, mostrou-se uma ferramenta de grande importância para a tomada de decisão e para a manutenção das atividades suinicolas e o equilibrio ambiental da bacia hidrográfica.

Palavras-chave: Contaminação Ambiental. Efluentes Suínos. Recursos Hidricos. Modelo Quali-quanitativo.

Abstract

The intensified use of natural resources started after the industrial revolution, with increasing the disorderly occupation of watersheds and environmental degradation over the past century. Studies of environmental fragilities helps to identify areas with greater or lesser fragility regarding to certain aspect or activity analyzed, contributing to the decision making and adoption of strategies to minimize such impacts. The objective of the study was to evaluate the environmental fragility of Lajeado Erval Novo Watershed front the swine farming in order to subsidize the support of the decision taken for the environmental licensing system. Therefore, was held an integrated environmental assessment of the basin from data processing in Geographic Information System using a model based on qualitative and quantitative variables and adding socio-environmental characteristics to hierarchize areas with higher and lower environmental fragility for swine effluents. The areas to the southwest and northeast of the studied watershed were diagnosed as points of high environmental fragility. This fragility was, mainly, related to higher generation of swine effluent load and the conditions that contribute to the process of environmental embrittlement of areas, such as the use and soil type, slope and proximity to water resources. The mapping of environmental fragilities, by addressing the specifics variables and conditions of areas, proved to be a very important tool for decision-making and the maintenance of swine activities and the environmental balance of the watershed. 


\section{Introdução}

Atualmente, o Brasil é o $4^{\circ}$ maior produtor mundial de suínos, possuindo um rebanho estimado em 42 milhões de cabeças, sendo a região Sul responsável por $69,0 \%$ do rebanho suíno brasileiro (ABCS, 2014). A atividade está concentrada em pequenas propriedades, com predomínio de mão de obra familiar, apresentando-se como o principal gerador de renda destes estabelecimentos. Contudo, a suinocultura apresenta um elevado ônus ambiental, devido ao grande volume de efluentes produzidos, que podem alcançar 7,5 L por dia para animais em terminação, totalizando aproximadamente 0,9 $\mathrm{m}^{3}$ de efluente para cada animal em um ciclo de 110 a 120 dias (PERDOMO et al., 2001).O efluente suíno é composto por urina, fezes, água do sistema de bebedouros e da limpeza, restos de ração, poeiras, pelos e qualquer outro material proveniente do sistema de criação, sendo que, para cada 10,0 L de água consumida no sistema de criação, são gerados, aproximadamente 6,0 L de efluentes (KONZEN, 1997; EPAGRI-CIRAM, 2000).

As áreas das propriedades suinícolas, geralmente, apresentam elevadas declividades, o que pode potencializar a transferência de nutrientes, principalmente, por escoamento superficial, mas também, por percolação, contaminando mananciais de águas superficiais e subsuperficiais (CERETTA et al., 2010; GIROTTO et al., 2013; LOURENZI et al., 2015). Além disso, devido à solubilidade de muitos compostos presentes nos efluentes suínos, o impacto ambiental provocado pela destinação inadequada de efluentes sem o devido tratamento, pode causar uma série de consequências, pela facilidade de transporte junto aos mananciais hídricos, como a eutrofização da água (KUNZ, 2007).

A água é um recurso natural que tem despertado a atenção de diversos setores da sociedade devido aos altos índices de poluição, tanto dos recursos hídricos superficiais, quanto dos subterrâneos, causando impactos ambientais, sociais e econômicos. Tomam-se, assim, as bacias hidrográficas como territórios ideais para o planejamento da gestão ambiental. Nesse sentido, o estudo de fragilidades ambientais em bacias hidrográficas contribui na identificação e caracterização de áreas que possam estar susceptíveis aos impactos ambientais gerados pelas diversas atividades localizadas nestas regiões.

Dessa forma, as análises de fragilidades contribuem nas tomadas de decisões estratégicas, que visam à diminuição dos impactos potenciais existentes, além de subsidiar o planejamento e a gestão ambiental de determinada área. De acordo com Ross (1994), a fragilidade dos ambientes naturais, associada às intervenções humanas é maior ou menor em função de suas características genéticas, tornando fundamental a identificação dos aspectos associados ao levantamento dos tipos de solo, clima, geomorfologia e demais componentes da área em que se deseja estudar sua suscetibilidade natural.

Assim, para a análise das fragilidades ambientais, entende-se que os elementos sejam estudados holisticamente, pautados na perspectiva sistêmica, envolvendo aspectos físicos, bióticos e socioeconômicos. Neste contexto, o objetivo deste trabalho foi analisar a fragilidade ambiental em decorrência da produção e destinação dos efluentes de suínos na Bacia Hidrográfica do Lajeado Erval Novo.

\section{Material e métodos}

\subsection{Localização e caracterização da área de estudo.}

A Bacia Hidrográfica do Lajeado Erval Novo encontra-se na área central da Região Noroeste do Estado do Rio Grande do Sul (Figura 1), integrando os municípios de Três Passos, Humaitá e Bom Progresso, fazendo parte da Bacia hidrográfica dos Rios Turvo, Santa Rosa e Santo Cristo - Bacia U030 (SEMA, 2005) e compõe parte da Região Hidrográfica do Uruguai. A bacia possui uma área de aproximadamente $98 \mathrm{~km}^{2}$, correspondendo a $0,9 \%$ da Bacia U030, tendo seu deságue no Rio Lajeado Grande e, posteriormente, no Rio Uruguai.

As precipitações médias anuais estão em torno de $1.900 \mathrm{~mm}$, segundo o Instituto Nacional de Meteorologia (INMET). O clima em todo o Noroeste do Rio Grande do Sul é definido como subtropical úmido, tipo Cfa, caracterizado pela presença de inverno frio, verão quente e inexistência de estação seca (KÖPPEN; GEIGER, 1928).

A Bacia Hidrográfica do Lajeado Erval Novo caracteriza-se pela grande quantidade de cursos d'água, formada por vários afluentes que deságuam no Lajeado Erval Novo, característica esta das áreas mais declivosas. Outra característica importante da bacia é o cultivo agrícola nas áreas mais planas e na região localizada mais ao sul, entre os municípios de Humaitá e Bom Progresso, onde predominam lavouras de culturas anuais, como milho e soja no verão e trigo e pastagens no inverno (LUIZ et al. 2017). Na bacia, a pecuária apresenta grande importância possuindo um expressivo número de aves, bovinos de leite e, principalmente, suínos. 
Figura 1 - Localização da bacia hidrográfica do Lajeado Erval Novo

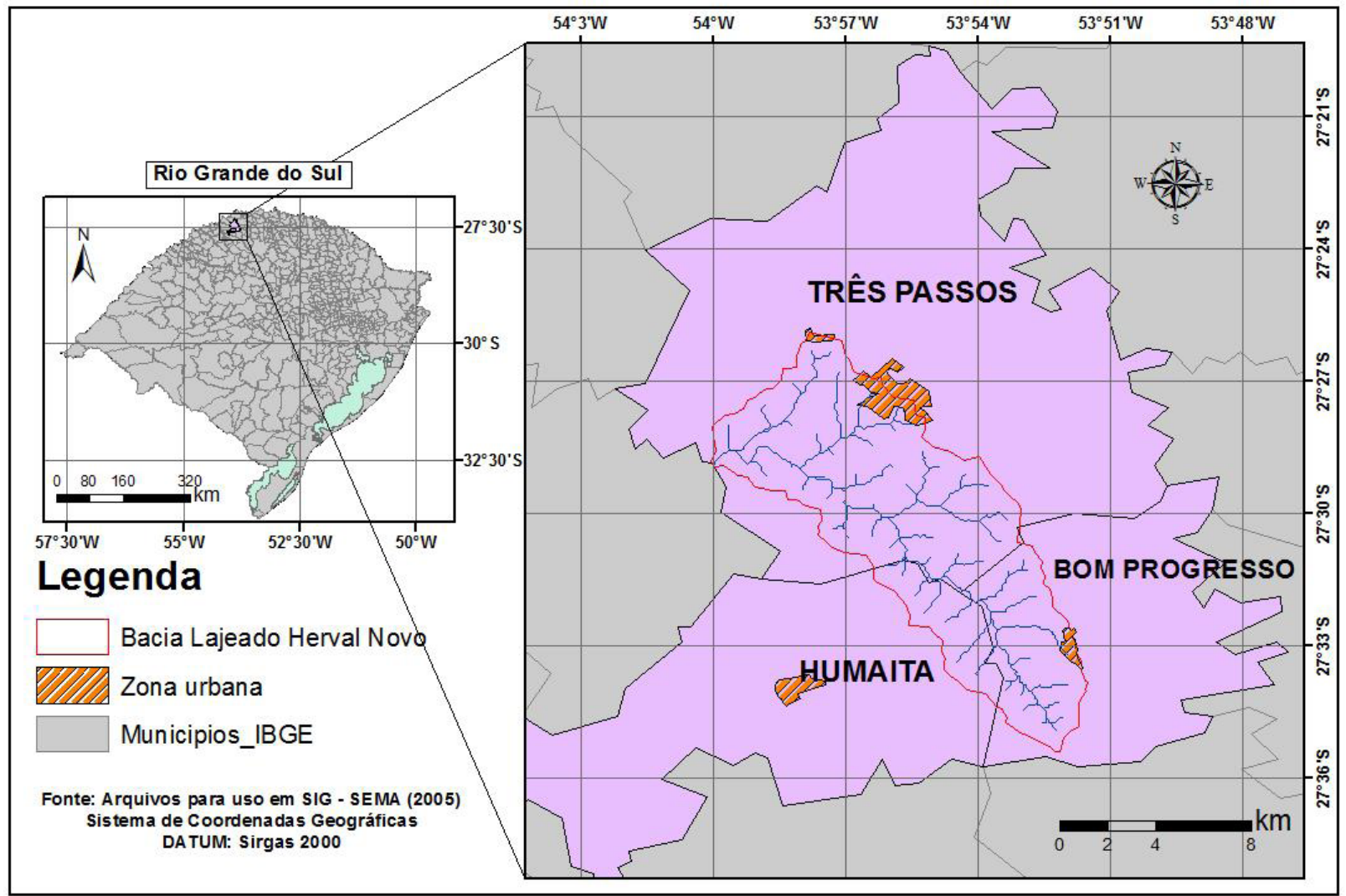

\subsection{Modelo quali-quantitativo utilizado}

Para atingir o objetivo da pesquisa, foram analisados os elementos da paisagem que integram à produção do efluente suíno por meio da elaboração de um mapa conceitual. Os conceitos-chaves foram dispostos e estruturados de maneira a relacionarem as caraterísticas do ambiente com a produção dos efluentes de suínos. Dessa forma, definiram-se variáveis que representam as fragilidades ambientais da bacia hidrográfica, identificando-se os respectivos indicadores dessas variáveis, para fins de mapeamento. Assim, buscando avaliar as fragilidades ambientais da bacia frente à atividade suinícola, utilizou-se um modelo baseado em variáveis quali-quantitativas, as quais refletem as principais características que influenciam na capacidade de suporte do ambiente frente à possibilidade de contaminação por efluentes suínos.

Através do processamento em SIG dos dados de produção de efluente da atividade da suinocultura, obtidos junto a Secretaria Municipal de Meio Ambiente de Três Passos, dados de sensoriamento remoto (FEPAM, 2001; HASENACK; WEBER, 2010; USGS, 2015) e literatura existentes, procurou-se mapear áreas com cargas potenciais de produção de efluentes suínos e avaliar a fragilidade deste ambiente de acordo com suas características geomorfológicas e sociais. O processamento digital foi executado no software ArcGis 10.2 (ESRI, 2014), somando as variáveis em forma de mapas com diferentes pesos de influência. A soma foi realizada pixel a pixel através da ferramenta Map Algebra, projetados em um mesmo Datum de referência (SIRGAS 2000). Este algoritmo apresenta um conjunto de operações em um SIG que permite interações entre duas ou mais camadas raster para produzir uma nova camada usando operações algébricas como por exemplo adição ou subtração (ESRI, 2014).

As variáveis consideradas para este estudo são compostas por indicadores que recebem notas conforme o grau de fragilidade. Essas notas são os valores atribuídos a cada pixel dentro de uma escala que, no mapa algébrico final, representa o quão frágil é este ambiente, baseado nessas variáveis. A fim de facilitar o processamento das imagens, delimitaram-se as notas na escala de 1 a 255 pontos, tendo em vista o byte, que é capaz de armazenar 256 informações diferentes. A síntese das variáveis com seus respectivos pesos e os indicadores com as notas utilizadas para este estudo está na Tabela 1, sendo que nas áreas de menor fragilidade foi atribuída nota 1 e para as áreas com fragilidade máxima, nota 255 . 
Tabela 1 - Variáveis e indicadores utilizados na construção do modelo de fragilidades ambientais da Bacia Hidrográfica do Lajeado Erval Novo

\begin{tabular}{|c|c|c|}
\hline Variáveis / Peso * & Indicadores & Notas $* *$ \\
\hline $\begin{array}{l}\text { Área com carga potencial para efluente suíno } \\
\qquad \mathbf{3 0} \%\end{array}$ & $\begin{array}{c}\text { Densidade }<1000 \mathrm{~m}^{3} / \mathrm{km}^{2} \\
\text { Densidade de } 1000 \text { a } 1150 \mathrm{~m}^{3} / \mathrm{km}^{2} \\
\text { Densidade de } 1150 \text { a } 1400 \mathrm{~m}^{3} / \mathrm{km}^{2} \\
\text { Densidade }>1400 \mathrm{~m}^{3} / \mathrm{km}^{2}\end{array}$ & $\begin{array}{l}64 \\
128 \\
192 \\
255\end{array}$ \\
\hline $\begin{array}{l}\text { Uso do solo } \\
\quad 20 \%\end{array}$ & $\begin{array}{l}\text { Lavoura, pastagem e solo exposto } \\
\text { Vegetação arbórea com dossel contínuo } \\
\text { Zona Urbana } \\
\text { Água }\end{array}$ & $\begin{array}{l}255 \\
64 \\
128 \\
128\end{array}$ \\
\hline $\begin{array}{l}\text { Declividade } \\
15 \%\end{array}$ & $\begin{array}{c}0-6^{\circ} \\
6-12^{\circ} \\
12-20^{\circ} \\
20-31,6^{\circ}\end{array}$ & $\begin{array}{c}1 \\
64 \\
128 \\
255\end{array}$ \\
\hline $\begin{array}{l}\text { Tipo de Solo } \\
\quad 15 \%\end{array}$ & $\begin{array}{l}\text { Latossolo Vermelho } \\
\text { Neossolo/Chernossolo }\end{array}$ & $\begin{array}{l}128 \\
255\end{array}$ \\
\hline $\begin{array}{l}\text { Distância dos Recursos Hídricos } \\
\qquad 20 \%\end{array}$ & $\begin{array}{c}50 \text { metros } \\
50 \text { a } 100 \text { metros } \\
100 \text { a } 200 \text { metros } \\
200 \text { a } 500 \text { metro } \\
>500 \text { metros }\end{array}$ & $\begin{array}{c}255 \\
192 \\
128 \\
64 \\
1\end{array}$ \\
\hline
\end{tabular}

*Escala de 0 a $100 \%$.**Escala de 1 a 255 pontos.

\subsubsection{Potencial de geração de cargas de efluentes suínos}

Primeiramente, para estimar a produção de efluentes suínos na bacia hidrográfica, realizou-se uma coleta de dados dos produtores de suínos da região licenciados junto à Secretaria Municipal do Meio Ambiente do município de Três Passos, obtendo-se um total de 28 estabelecimentos de criação de suínos nos sistemas de creche e terminação. O porte dos criatórios apresentou variação de pequeno a grande, com capacidade de alojamento para até 1000 cabeças de suínos por ciclo no sistema de terminação e até 5000 cabeças no sistema de creche. Estes estabelecimentos tiveram sua capacidade nominada pela Resolução do Conselho Estadual do Meio Ambiente (CONSEMA) (CONSEMA, 2014), que atualizou os tipos e portes das atividades que podem causar impacto ambiental no âmbito municipal.

Obtidos os dados de produção com suas respectivas coordenadas geográficas, procedeu-se uma estimativa de geração de efluente suíno, baseado nos dados de Perdomo et al. (2001), os quais afirmam que a produção de efluentes suínos é de aproximadamente 7,5 e 14,0 L dia-1 para animais em fase de terminação e na criação em creches, respectivamente. A avaliação das áreas de produção de efluentes suínos foi realizada através da análise da densidade de cargas potenciais anuais (Tabela 1), inseridas em cada sub-bacia que compõe a área de estudo. A atribuição de notas a esta variável ocorreu de acordo com a quantidade potencial de efluente suíno lançado por $\mathrm{km}^{2}$.ano ${ }^{-1}$. Foi possível então estimar a produção de efluentes suínos por unidade de área e quais as regiões mais frágeis à poluição por estes efluentes (Figura 2). 
Figura 2 - Sub-bacias da Bacia Hidrográfica do Lajeado Erval Novo com as respectivas potenciais cargas anuais de efluente suíno

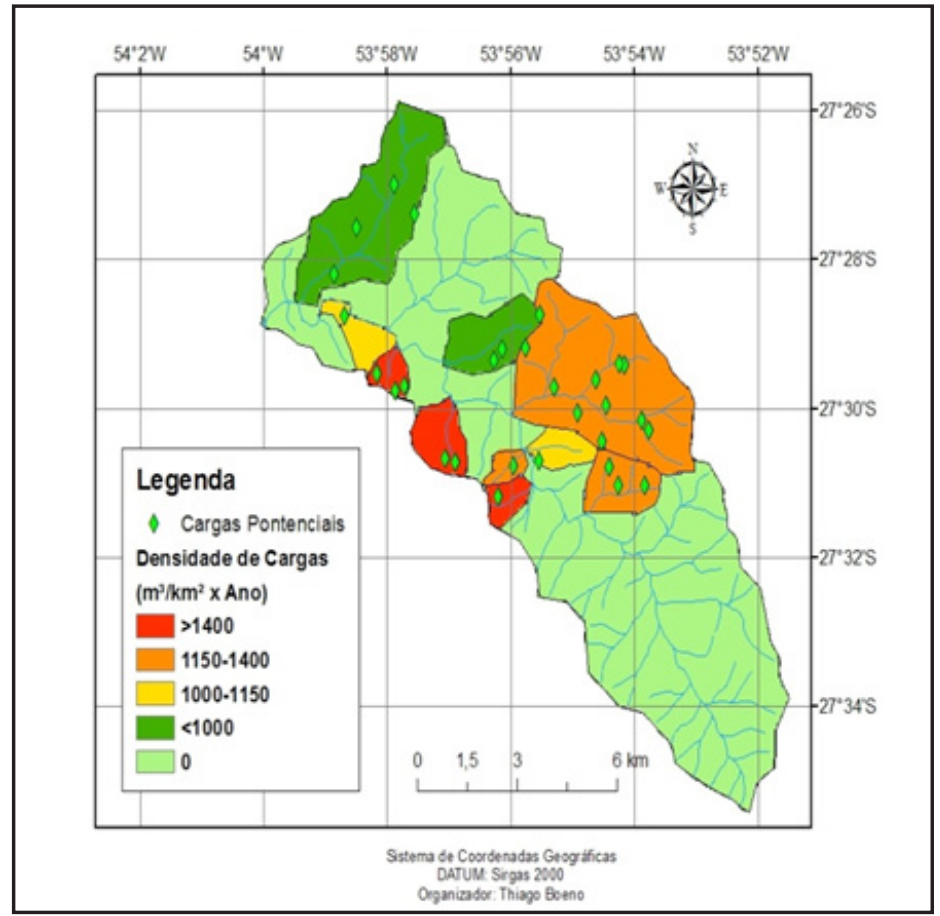

\subsubsection{Uso do Solo}

O mapa de uso do solo da bacia (Figura 3) em estudo foi construído utilizando a abordagem de classificação não supervisionada da imagem de satélite Landsat 5 TM (USGS, 2015) e elaborada através de sistema de informação geográfica. Nesta etapa, utilizou-se os padrões de cores da imagem de satélite para mapear áreas da superfície terrestre que correspondem aos principais aspectos de interesse nesse estudo.

Figura 3 - Imagem da área da Bacia Hidrográfica do Lajeado Erval Novo, obtida pelo satélite Landsat em falsa cor à esquerda e mapa de uso do solo produzido a partir de classificação supervisionada à direita

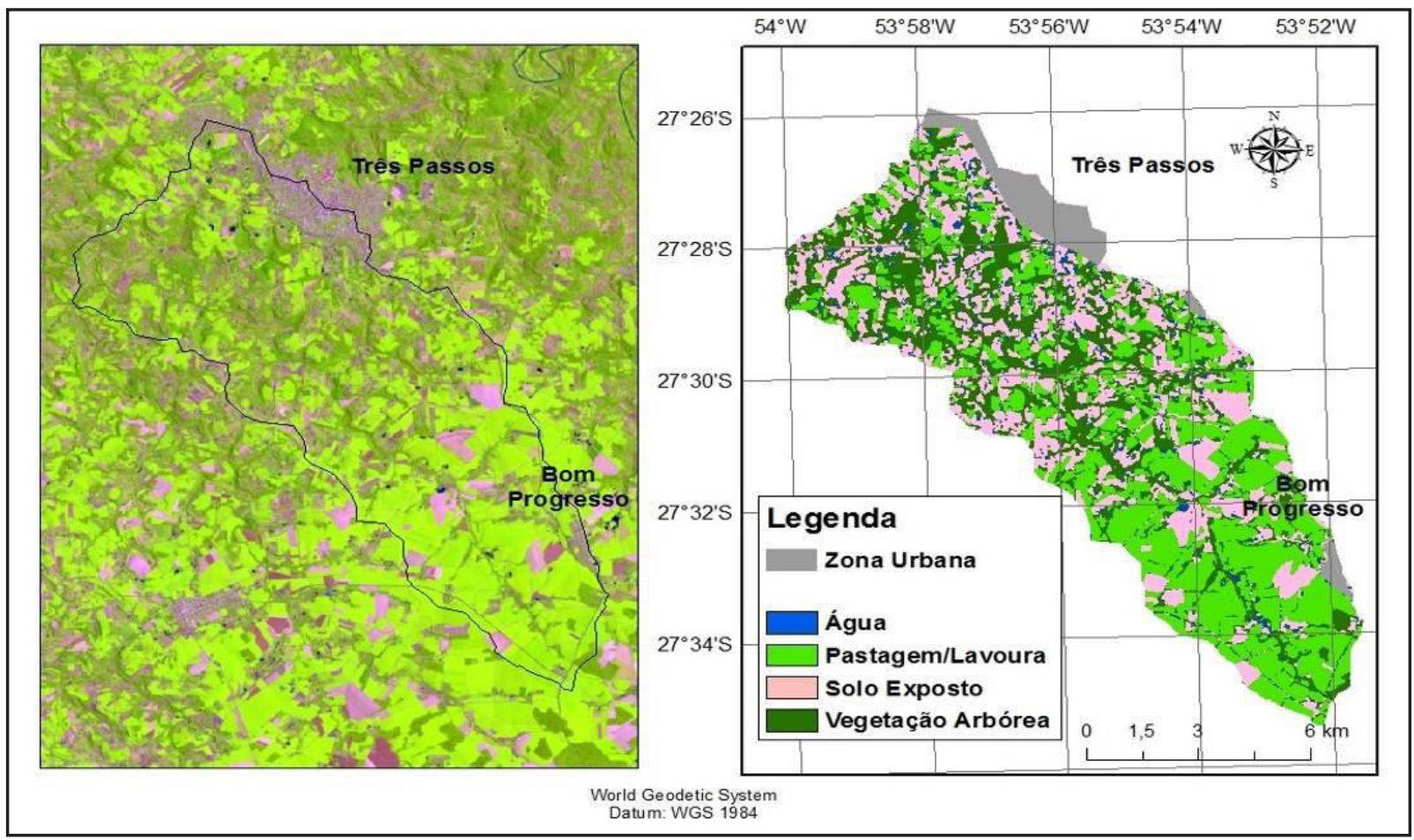


Identificou-se os tipos de cobertura de solos, de acordo com os padrões de resposta espectral (classificação de cada pixel) dos elementos da imagem. Para a classificação, utilizou-se o algoritmo Iso Cluster, onde as classes dos padrões espectrais são determinadas pela análise de agrupamentos. Assim, classificaram-se os pixels da zona urbana, área com água exposta, pastagens/lavouras, solo exposto e vegetação arbórea.

Por fim, baseado na imagem de satélite, obteve-se um arquivo no formato raster com informação da nota atribuída em cada pixel, correspondente ao atributo da dinâmica de uso e de cobertura do solo. É possível observar por meio das imagens da Figura 3 que o procedimento utilizado foi satisfatório, uma vez que a classificação captou as características básicas de utilização da bacia.

\subsubsection{Classes de solos, declividades e distância dos recursos hídricos.}

Para definição das classes de solos, utilizou-se como base o mapa de solos do Rio Grande do Sul (STRECK et al., 2008), sendo diagnosticados na área de estudo, principalmente, Latossolo Vermelho nas áreas altas, apresentando fragilidade baixa, e uma associação de Neossolo Litólico e Chernossolo Argilúvico nas demais áreas, as quais foram consideradas mais vulneráveis (Tabela 1).

Ainda em relação às classes de solos, utilizou-se o critério estabelecido pela Fundação Estadual de Proteção Ambiental do Rio Grande do Sul (FEPAM, 2001) em seu relatório final de classificação dos solos do Estado do Rio Grande do Sul, quanto à resistência a impactos ambientais baseado em suas características físico-químicas. Esse relatório classificou o Latossolo Vermelho como tendo baixa propensão a impacto ambiental, pois tratam-se de solos profundos, bem drenados, com elevado teor de argila (mais de 60\% de argila) e óxidos em todo o perfil, encontrados em relevo ondulado, formado por declives curtos em dezenas de metros e declives variáveis de 5 a 15\% (STRECK et al., 2008). Estas características conferem a estes solos uma grande capacidade de aporte de nutrientes, oriundos dos efluentes suínos sem que ocorram perdas, especialmente por escoamento superficial, quando adotadas práticas de manejo de conservação do solo. Atribuiu-se a este solo uma nota de 128 pontos para cada pixel, devido à menor propensão a impactos ambientais.

Por outro lado, a associação formada por Neossolo Litólico e Chernossolo Argilúvico, é caracterizada por solos pouco desenvolvidos, com elevada pedregosidade e pequena profundidade. Estes solos apresentam limitações de uso, principalmente devido ao risco de erosão, pois geralmente ocorrem em relevo ondulado ou fortemente ondulado, possuindo elevada propensão a impactos ambientais e, por isso, designou-se uma nota de 255 pontos, para cada pixel que possui esta associação de solos.

Os dados de declividade foram extraídos por geoprocessamento através do Modelo Numérico do Terreno (MNT) do Shuttle Radar Topography Mission (SRTM) com resolução de 30 metros, obtidas junto ao United States Geological Survey (USGS). Foram estabelecidas quatro classes de fragilidade para a variável declividade, variando de muito fraca (1) a muito forte (255).

Considerando o grau de declividade, as áreas mais íngremes foram discriminadas como as de maior fragilidade, pois juntamente com o escoamento superficial, os efluentes chegam mais rapidamente nos cursos d'água. Desta forma, quanto menos declivosa a área, menor foi à nota estipulada em relação à fragilidade, pois estas áreas possuem maior capacidade de infiltração e, consequentemente, maiores quantidades de efluentes podem ser filtradas pelo solo.

Figura 4 - Mapa da variável classe de solo, declividade e distância dos recursos hídricos na Bacia Hidrográfica do Lajeado Erval Novo

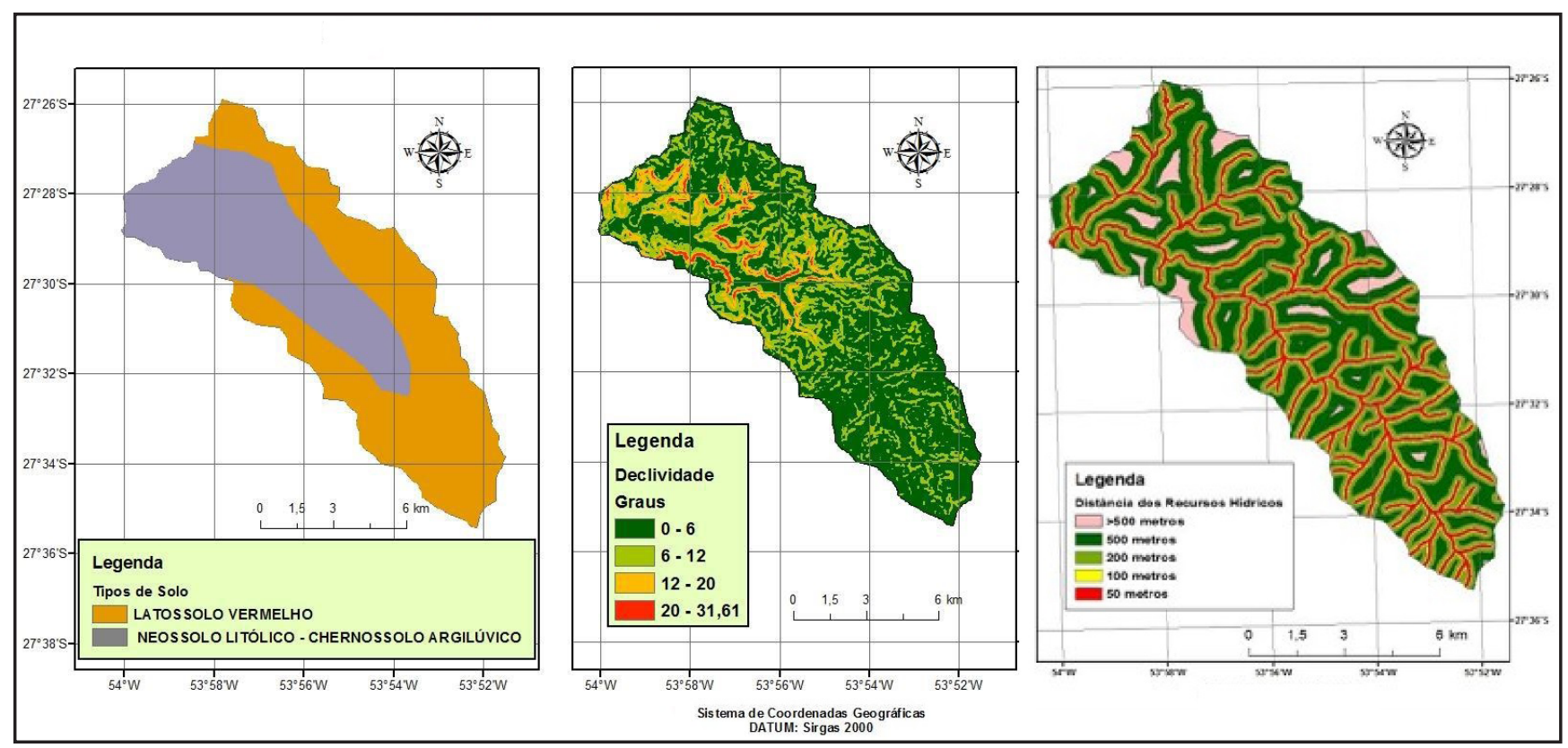


A avaliação das distâncias dos recursos hídricos foi realizada com base nas classes de proteção das áreas de preservação permanente descritas no Novo Código Florestal brasileiro (BRASIL, 2012), que determina as seguintes faixas de proteção: 30, 50, 100, 200 e 500 metros para rios perenes pertencentes ao território nacional.

Na elaboração deste mapa (Figura 4), utilizaram-se as informações constantes na Base Cartográfica Vetorial Contínua do Estado do Rio Grande do Sul, com escala 1:50.000 (HASENACK; WEBER, 2010), estabelecendo áreas com menor fragilidade na medida em que as áreas se distanciam da rede de drenagem (Tabela 1). Assim, as maiores notas foram atribuídas aos buffers menores, como o de até $50 \mathrm{~m}$ da rede de drenagem, diminuindo as mesmas na medida em que aumenta a distância das redes de drenagens (Figura 4).

Com o objetivo de geração de um mapa com as áreas que apresentam as maiores fragilidades ambientais em decorrência dos efluentes suínos na bacia, as variáveis selecionadas, mapeadas e com as respectivas notas as suas classes, foram submetidas a uma análise multicritério. Esta análise consiste em hierarquizar as variáveis mais representativas para este estudo de fragilidades ambientais.

Para estabelecimento dos pesos, utilizou-se o método de construção de consensos. Este método é caracterizado pela discussão entre diferentes profissionais multidisciplinares a fim de encontrar o peso ideal a cada variável. Inicialmente foram discutidas as variáveis destinando pesos iguais a elas. Posteriormente, baseado nos atributos físicos do ambiente da área de estudo, foram definidas quais variáveis eram mais representativas e possuíam maior importância na análise das fragilidades ambientais em uma bacia hidrográfica, para então estabelecer os pesos mais adequados ao problema delineado. Assim, conforme o peso atribuído a cada uma das variáveis, gerou-se o mapa de fragilidades ambientais, que é a síntese de todos os mapas produzidos (Figura 5), a partir das suas sobreposições, indicando as áreas de maior e menor fragilidade na bacia hidrográfica.

Figura 5 - Variáveis e respectivos pesos atribuídos no estudo de fragilidades ambientais

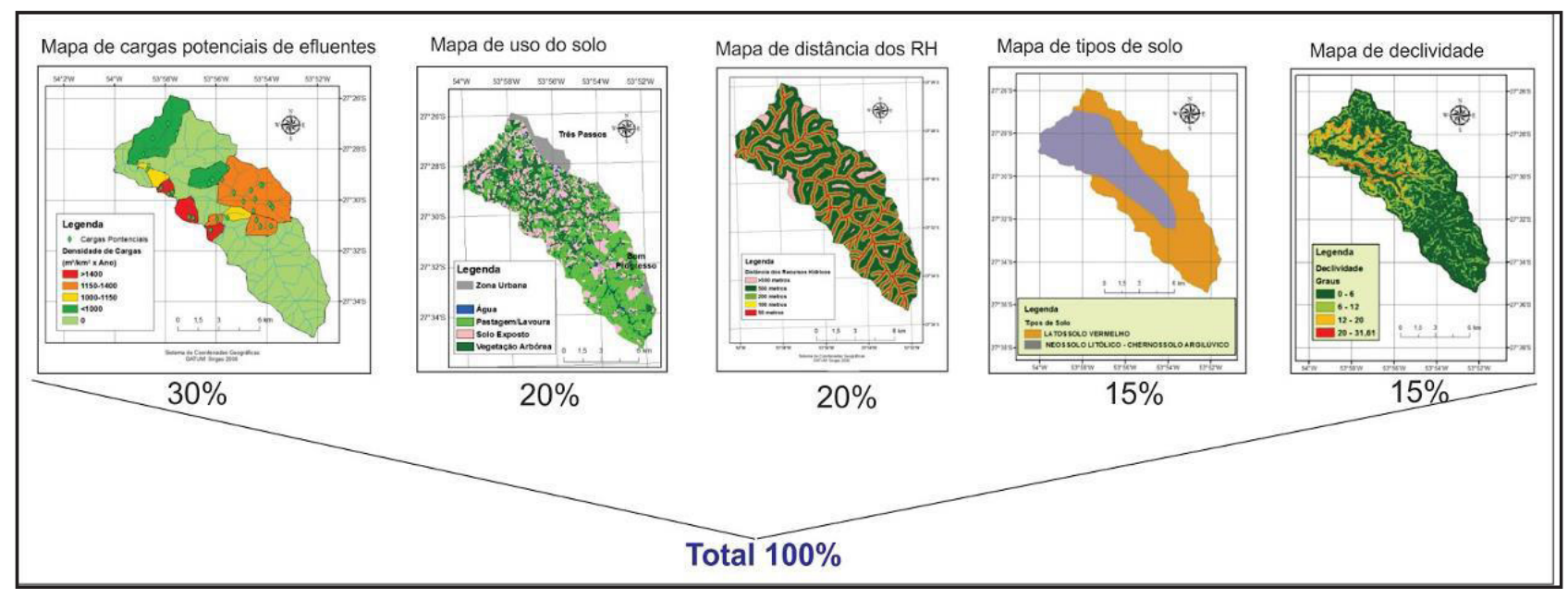

\section{Resultados e discussão}

Indicou-se uma série de impactos ambientais gerados pela atividade antrópica que poderão atingir, ao final, o abastecimento público de água, visto que o Lajeado Erval Novo é, atualmente, a principal fonte de captação da Companhia Rio Grandense de Saneamento (CORSAN), responsável pela distribuição de água potável à população de Três Passos. Estes impactos podem ser observados através da contaminação do solo, especialmente pelo escoamento superficial, que pode atingir os recursos hídricos (neste caso o Lajeado Erval Novo e seus afluentes), interferindo negativamente na qualidade da água.

Através do mapa das cargas potenciais anuais de efluentes suínos distribuídos em cada sub-bacia (Figura 2), observa-se uma concentração da produção na porção média, à jusante da Bacia Hidrográfica do Lajeado Erval Novo. A partir da análise dos mapas de solos, declividade (Figura 4) e uso da terra (Figura 3), observou-se que essa concentração de suínos possui relação com o tamanho das propriedades rurais. A concentração da suinocultura nestas áreas da bacia tem relação com o fato de serem áreas mais declivosas e com solos mais rasos, o que não favorece a atividade agrícola, em relação à outra parcela da bacia hidrográfica (à montante), que possui solos mais profundos, com menor declividade e com aptidão para o cultivo de grandes culturas anuais, como a soja, o milho e o trigo. Sendo assim, os produtores desenvolvem atividades que possibilitam a agregação de renda em pequenas áreas, como é o caso da suinocultura.

Neste cenário, as diferenças de solos e declividades têm influência no estabelecimento dos usos da terra e das atividades desenvolvidas pelas propriedades, configurando, também, a diferença no tamanho da área média das mesmas. Assim, a área de 
maior fragilidade ambiental, devido às características de solo e declividade, coincidentemente também possui maior fragilidade em relação à produção de efluentes suínos.

Esses efluentes podem ser utilizados na propriedade como fonte de nutrientes para culturas anuais ou pastagens. Porém, em razão da pequena extensão de terra das propriedades suinícolas, sucessivas aplicações de dejetos, normalmente, são realizadas na mesma área de cultivo, em muitos casos sobre solos rasos e declivosos (CERETTA et al., 2010), como no caso dos Neossolos e Chernossolos. Estas características contribuem para que ocorra a erosão do solo, o que potencializa a eutrofização de águas superficiais e subsuperficiais pela possibilidade de transferências de fósforo e nitrogênio pela solução escoada na superfície do solo (CERETTA et al., 2010; LOURENZI et al., 2015), bem como pela solução percolada no solo (GIROTTO et al., 2013).

Nessa conjuntura, foram elaborados os mapas de fragilidades ambientais (Figura 6), sendo o primeiro (A), desenvolvido com os pesos iguais para as variáveis e, o segundo (B), construído com pesos diferentes para cada variável (Tabela 1). Os mapas de fragilidades ambientais da Bacia Hidrográfica do Lajeado Erval Novo, ilustrados na figura 6, representam as potencialidades que cada variável possui, no que se refere à poluição, tanto da água quanto dos solos.

Figura 6 - Mapas comparativos de fragilidades ambientais da Bacia Hidrográfica do Lajeado Erval Novo

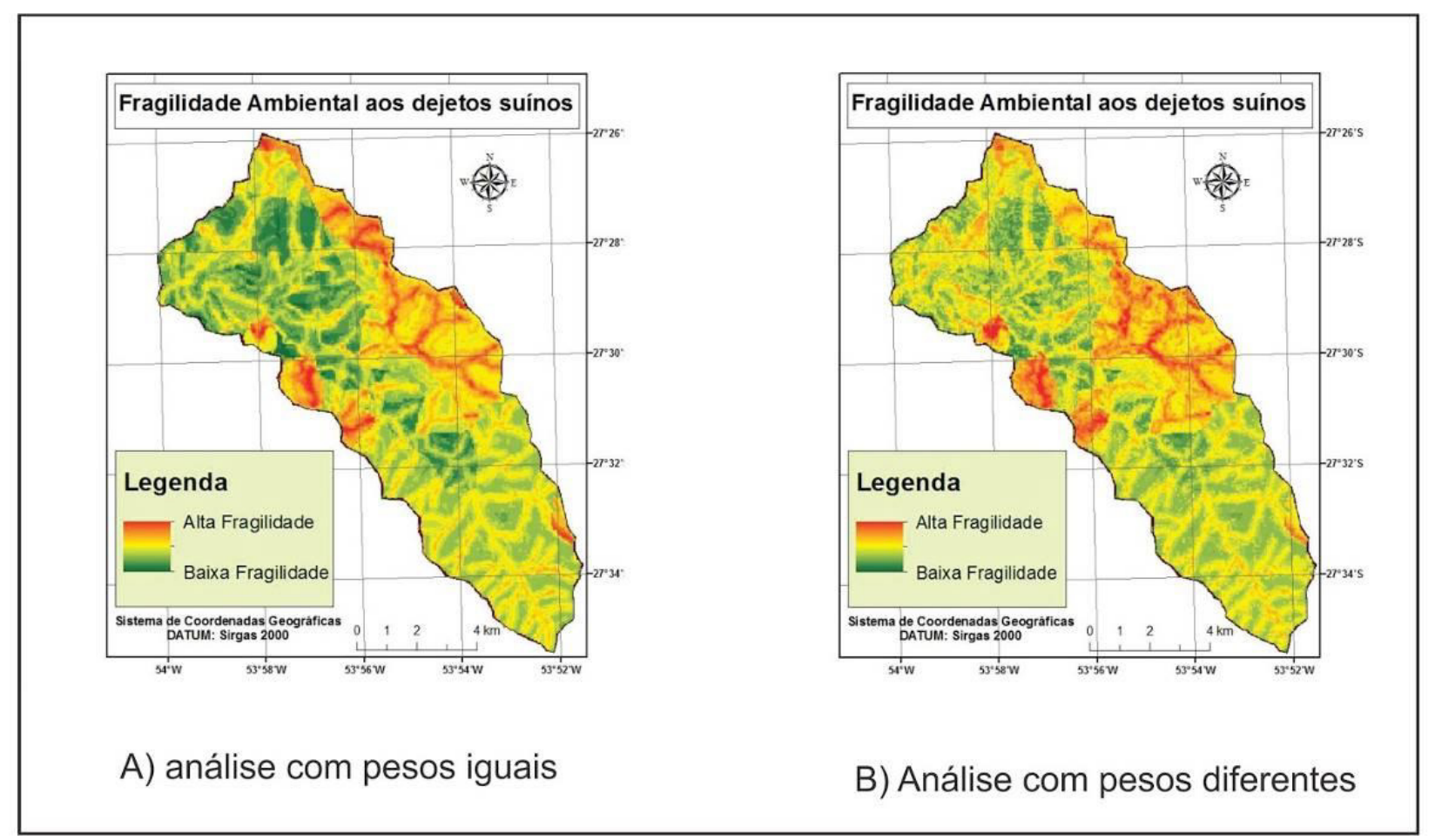

Verificou-se que o índice de fragilidade na bacia aumentou com a alteração dos pesos das variáveis. Isso porque, com $20 \%$ do peso atribuído na análise dos pesos iguais, as áreas de baixa fragilidade foram maiores na porção à jusante da bacia, em relação a mesma área no mapa realizado com a análise dos pesos diferentes. Assim, destaca-se a relevância de atribuição dos pesos diferentes, no qual as variáveis cargas potenciais de efluentes suínos e uso do solo tiveram maior influência na definição das áreas com maior fragilidade.

Este resultado foi considerado satisfatório para a pesquisa, pois ao analisar a área de estudo é possível observar que as áreas identificadas como de maior fragilidade ambiental, no mapa com pesos diferentes, estão de acordo com a realidade da bacia. Estas áreas são as de maior declividade, com tipo classe de solo Neossolo Litólico - Chernossolo Argilúvico e que condizem com as sub-bacias hidrográficas da bacia do Lajeado Erval Novo com maiores cargas de efluentes suínos.

O mapa final de fragilidades ambientais foi composto pela soma das informações tabuladas nos mapas com pesos diferentes, sendo eles: cargas potenciais de efluentes, uso do solo, distância dos recursos hídricos, tipos de solos e de declividade. Neste sentido, podemos identificar que os locais mais frágeis são a sudoeste e nordeste da bacia. O local com maior incidência de fragilidade na porção nordeste da bacia é devido às áreas de maior declividade e pela maior concentração de criadores de suínos (Figura 7). De acordo com Dai Prá (2009), o método de criação mais típico é o de confinamento, caracterizado pelo grande número de animais e pela geração de um grande volume de dejetos. Isto faz com que os produtores realizem anualmente a aplicação de grandes quantidades destes efluentes no solo, o que aliado às características de solo e relevo, potencializam os riscos de contaminação ambiental. 
Figura 7 - Local de instalação de granja produtora de suínos e com áreas de disposição declivosas ao fundo

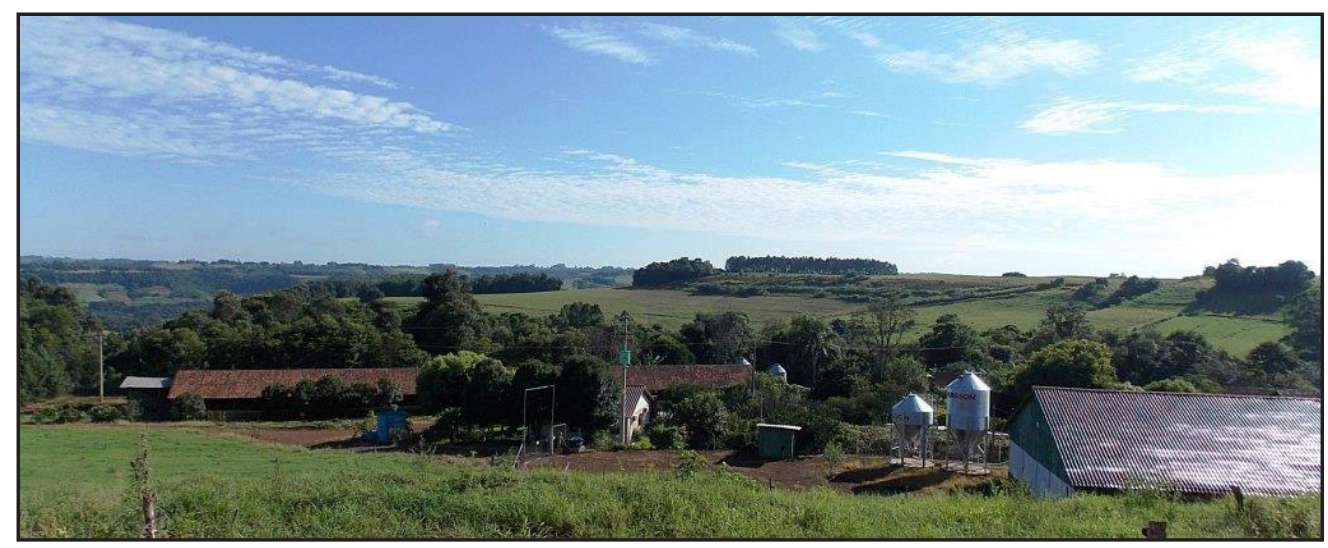

Na porção sudoeste da região é possível identificar um número menor de criadores, porém com um número expressivo de animais em sistema de criação, gerando uma descarga potencial superior a $1.400 \mathrm{~m}^{3} / \mathrm{km}^{2} /$ ano de efluentes suínos. O Estado de Santa Catarina possui a Instrução Normativa número 11/2004 (FATMA, 2014), que restringe a aplicação de dejetos líquidos de suínos no solo a uma dose máxima de $50 \mathrm{~m}^{3} /$ ha/ano. As propriedades localizadas na bacia estudada possuem área média total de 10 ha, contudo, considerando as áreas de preservação permanente, vegetação nativa e construções, a área agricultável das propriedades, disponíveis para a aplicação do efluente como fertilizante, pode variar de 6 a 8 ha. Considerando que nestas propriedades contenham instalações para a criação de 500 suínos em fase de terminação e com 2,5 ciclos (110 dias) de criação por ano, geraria-se aproximadamente $1.030 \mathrm{~m}^{3} /$ ano de efluentes, a serem dispostos em no máximo 8 ha. Isto representaria a adição de $128 \mathrm{~m}^{3}$ de efluente por hectare ao longo do ano, ou seja, mais que o dobro da carga aceitável pela instrução normativa catarinense. Com isso, aumenta a probabilidade do carreamento de nutrientes não adsorvidos aos coloides do solo, coliformes fecais, entre outros, que resultam em uma série de impactos ambientais diretos e indiretos causados pela má gestão dos efluentes, junto aos cursos hídricos e também ao solo.

Destaca-se, também, que na área sudoeste existe uma maior concentração de áreas de solo exposto, provavelmente utilizadas, na sua maior parte, para culturas anuais como soja, milho e trigo, mas que é caracterizada como de baixa fragilidade (Figura 8). De acordo com Gatiboni et al. (2014), os sistemas agrícolas podem causar a eutrofização das águas, através do fornecimento de água e sedimentos ricos em nutrientes, principalmente fósforo e nitrogênio, oriundos da disposição de efluentes suínos e da adubação química, aumentando a disponibilidade desse nutriente nos sistemas hídricos superficiais, como açudes, lagos, reservatórios de represas e redes de drenagem. Como forma de mitigar estes impactos, podem-se adotar algumas medidas de controle da erosão, desde curvas de níveis, terraceamento, cultivos em nível, implantação de espécies vegetais de acordo com o relevo na paisagem e cobertura do solo com plantas.

Figura 8 - Área a sudoeste da sub-bacia, com presença de culturas anuais, menor percentual de declividade e produtores de suínos

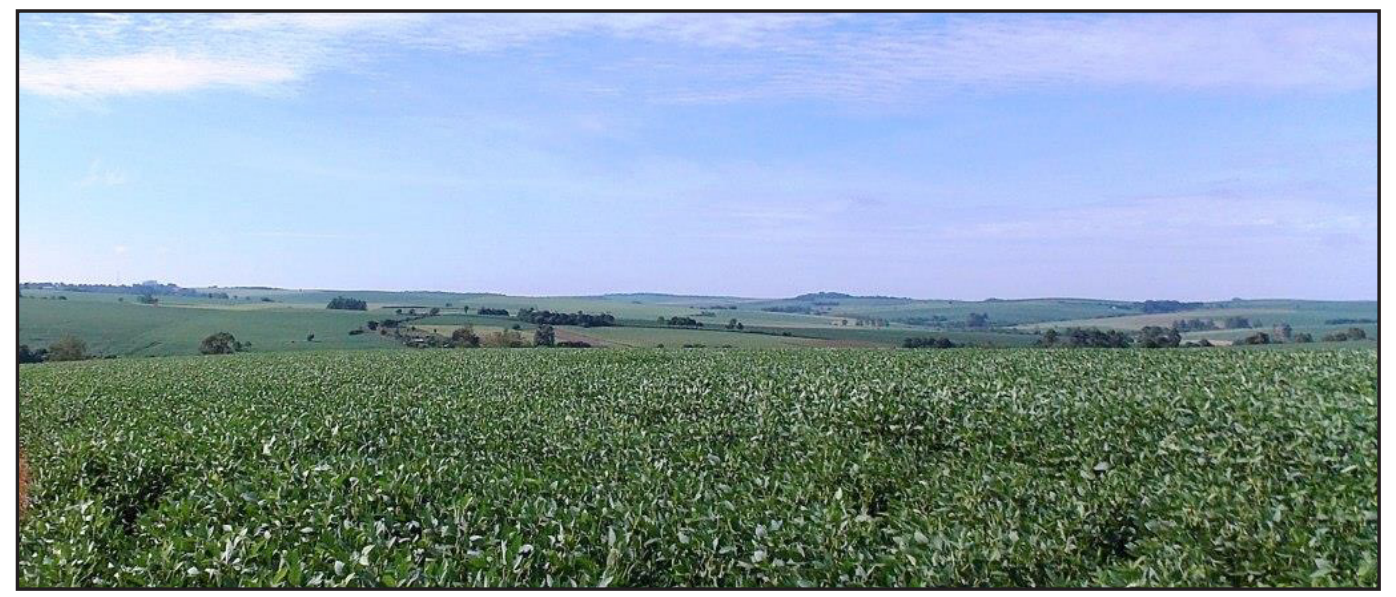

O estudo das fragilidades ambientais da Bacia Hidrográfica do Lajeado Erval Novo, apresentou variáveis com potencial para a manutenção do equilíbrio entre a produção de suínos e a qualidade ambiental, criando assim, ferramentas aptas para 
nortear gestores públicos e privados, nas tomadas de decisões sobre a gestão ambiental de novos criadores na região. No entanto, como enfatizado por Cardoso et al. (2015), o uso destas áreas necessita de um maior estudo e planejamento, bem como de uma visão sistêmica e holística do ambiente para a preservação e manutenção de padrões ambientais aceitáveis.

\section{Conclusões}

A escolha das variáveis, através de um mapa conceitual, mostrou-se uma ferramenta capaz de identificar os principais elementos que influenciam na fragilidade ambiental decorrente da atividade suinícola. As variáveis utilizadas para avaliação mostraram-se satisfatórias, possibilitando a identificação dos principais fatores que são importantes para a avaliação da suscetibilidade ambiental da Bacia Hidrográfica do Lajeado Erval Novo em relação à suinocultura.

A partir da composição e integração dos dados, bem como dos mapas elaborados pelas diferentes variáveis que constituíram o estudo, foi possível elaborar o mapa de fragilidade ambiental, que permitiu identificar as áreas mais frágeis, localizadas à sudoeste e nordeste na bacia. Estas áreas possuem concomitantemente solos rasos e pouco desenvolvidos, elevadas declividades e o maior rebanho de suínos, com a consequente maior produção de efluentes.

Desta forma, as áreas classificadas como de alta fragilidade, requerem políticas públicas direcionadas à minimização dos impactos ambientais decorrentes da atividade de suinocultura, contribuindo para tomada de decisão dos órgãos responsáveis por novos licenciamentos ambientais na região onde foi efetuado o estudo.

\section{Referências}

ABCS. Associação Brasileira de Criadores de Suínos. ABCS e representantes de agroindústrias se reúnem para discutir Projeto de Lei sobre produção integrada. Disponível em: http://www.abcs.org.br/informativo-abcs. Acesso em: 18 de fev.2015.

BRASIL. Lei n. 12.651 de maio de 2012. Dispõe sobre a proteção da vegetação nativa; altera as Leis nos 9.393, de 19 de dezembro de 1996, e 11.428, de 22 de dezembro de 2006; revoga as Leis nos 4.771, de 15 de setembro de 1965, e 7.754, de 14 de abril de 1989, e a Medida Provisória no 2.166-67, de 24 de agosto de 2001; Diário Oficial [da] Presidência da República: Casa Civil, Brasília, DF, 15 set. 1965. Disponível em:

http://www.planalto.gov.br/ccivil_03/_ato2011-2014/2012/lei/112651.htm. Acesso em: 14 fev. 2016.

CARDOSO, O., ROCHA, N. D., XAVIER, R., VAlDUGA, E., DISCONZI, G., RADTKE, L., CRUZ, R. C. Análise de fragilidade ambiental na bacia do rio Pardo - RS, frente à instalação de pequenas centrais hidrelétricas (PCHs). Revista Brasileira de Recursos Hídricos. 2015; 20(2): 507-522.

CERETTA, C. A.; GIROTTO, E.; LOURENZI, C. R.; TRENTIN, G.; VIEIRA, R. C. B.; BRUNETTO, G. Nutrient transfer by runoff under no tillage in a soil treated with successive applications of pig slurry. Agriculture, ecosystems \& environment, 2010; 139(4): 689-699.

CONSEMA. Conselho Estadual do Meio Ambiente. Resolução nº 288/2014 - Atualiza e define as tipologias, que causam ou que possam causar impacto de âmbito local, para o exercício da competência Municipal para o licenciamento ambiental, no Estado do Rio Grande do Sul. Disponível em: https://www.legisweb.com.br/legislacao/?id=275464. Acesso em: 22 fev. 2016.

DAI PRÁ, M. A. Compostagem como alternativa para gestão ambiental na produção de suínos. Porto Alegre: Evangraf, 2009. 143p.

EPAGRI. Centro Integrado de Informações de Recursos Ambientais - CIRAM. Inventário das terras da sub-bacia hidrográfica do rio Coruja/Bonito. Florianópolis/SC: EPAGRI - CIRAM, 2000, 112 p.

ESTADO DO RIO GRANDE DO SUL/SEMA - Secretaria Estadual de Meio Ambiente - Bacias hidrográficas e municípios do Rio Grande do Sul. Mapa. 2005.

ESRI. ArcGIS for Desktop. Estados Unidos da América. Versão 10.2.2. 2014.

FATMA. Fundação do Meio Ambiente de Santa Catarina. Instrução Normativa 11 de 13/12/2004. Disponível em: http://www. fatma.sc.gov.br. Acesso em: 24 mar. 2016. 
FEPAM. Fundação Estadual de Proteção Ambiental Henrique Luis Roessler. Mapa de Classificação dos Solos do Estado do Rio Grande do Sul quanto à Resistência a Impactos Ambientais. Porto Alegre: FEPAM. 13 p. Relatório final de consultoria elaborado por Nestor Kämpf. Mapa em meio digital. 2001.

GATIBONI, L. C., SMITH, T. J., SCHMITT, D. E., CASSOL, P. C., OLIVEIRA, C. M. B. Proposta de limites críticos ambientais de fósforo para solos de Santa Catarina (Boletim Técnico). Lages: UDESC/CAV, 38 p., 2014.

GIROTTO, E., CERETTA, C. A., LOURENZI, C. R., LORENSINI, F., TIECHER, T. L., VIEIRA, R. C. B., BRUNETTO, G. Nutrient transfers by leaching in a no-tillage system through soil treated with repeated pig slurry applications. Nutrient cycling in agroecosystems, 2013; 95(1): 115-131.

HASENACK, H.; WEBER, E.(org.) Base cartográfica vetorial contínua do Rio Grande do Sul - escala 1:50.000. Porto Alegre: UFRGS Centro de Ecologia. 2010. 1 DVD-ROM. (Série Geoprocessamento n.3). ISBN 978-85-63483-00-5 (livreto) e ISBN 978-85-63843-01-2 (DVD).

KONZEN, E. A. Valorização Agronômica dos Dejetos Suínos: utilização dos dejetos suínos como fertilizantes. Ciclo de palestras sobre dejetos suínos no sudoeste goiano, Rio Verde, GO, 1997.

KÖPPEN, W.; GEIGER, R. Klimate der Erde. Gotha: Verlag Justus Perthes. Wall-map 150cm x 200cm, 1928.

KUNZ, A.; Adaptação Ambiental da suinocultura: uma visão global. In: XIII Congresso Brasileiro de Veterinários Especialistas em Suínos (ABRAVES), Florianópolis. Anais... Florianópolis: Associação Brasileira de Veterinários Especialistas em Suínos, p. 1-8, 2007.

LOURENZI, C. R., CERETTA, C. A., TIECHER, T. L., LORENSINI, F., CANCIAN, A., STEFANELLO, L., BRUNETTO, G. Forms of phosphorus transfer in runoff under no-tillage in a soil treated with successive swine effluents applications. Environmental monitoring and assessment. 2015; 187(4): 1-16.

LUIZ, T. B. P., SILVÉRIO DA SILVA, J. L., SCHRÖDER, T., DESCOVI FILHO, L. L. V. Mapeamento de risco de sodificação de solos em microbacia hidrográfica no Rio Grande do Sul. Revista Verde de Agroecologia e Desenvolvimento Sustentável. 2017 ; $12(1)$ : 68-73.

MINISTÉRIO DO MEIO AMBIENTE - MMA. Relatório FRAG-RIO: apresentação do relatório e equipe técnica. Departamento de Licenciamento e Avaliação Ambiental, 2009.

PERDOMO, C. C.; LIMA, G. J. M. M.; NONES, K.; LIMA, M.; CABRAL, O.; MIGUEZ, J. Suinocultura e Estratégias para redução de Gases e Poluentes. Mudanças Climáticas Globais e a Agropecuária Brasileira. Jaguariúna: EMBRAPA/CNPMA, p. 325-45, 2001

ROSS, J. L. S. Análise empírica da fragilidade dos ambientes naturais e antropizados. Revista do Departamento de Geografia. 1994 ; 8: 63-74.

STRECK, E. V.; KÄMPF, N.; DALMOLIN, R. S. D.; KLAMT, E.; NASCIMENTO, P. C. do; SCHNEIDER, P.; PINTO, L. F. S. Solos do Rio Grande do Sul. 2. ed. Porto Alegre: EMATER/RS, 2008. 222 p.

UNITED STATES GEOLOGICAL SURVEY - USGS. Landsat-5 (TM). Disponível em:http://landsat.usgs.gov. Acesso em: 23 mai. 2015.

\section{Fernanda Maria Follmann}

Universidade Federal de Santa Maria, Campus de Santa Maria, Santa Maria, RS, Brasil, Email:ferfollmann@yahoo.com.br

Participação do autor: Trabalhou na concepção, elaboração da metodologia, revisão bibliográfica, análise e interpretação dos dados, redação e revisão do artigo;

\section{Júlia Caetano Manfio}

Universidade Federal de Santa Maria, Campus de Santa Maria, Santa Maria, RS, Brasil, Email:julia_manfio@yahoo.com.br

Participação do autor: Trabalhou na concepção, elaboração da metodologia, revisão bibliográfica, redação e revisão do artigo; 


\section{Rafael Cabral Cruz}

Universidade Federal do Pampa, Campus de São Gabriel, São Gabriel, RS, Brasil Email: rafaelcruz@unipampa.edu.br

Participação do autor: estruturação do artigo e auxiliou na concepção, elaboração da metodologia, elaboração dos mapas, análise e interpretação dos dados, revisão crítica do artigo e aprovação da versão a ser publicada.

\section{Robson Evaldo Gehlen Bohrer}

Universidade Estadual do Rio Grande do Sul - UERGS - Três Passos. RS, Brasill.

Email: gehlen.bohrer@gmail.com

Participação do autor: trabalhou na concepção, revisão bibliográfica, elaboração da metodologia, coleta e interpretação dos dados, da discussão dos resultados e da redação do texto

\section{Tadeu Luis Tiecher}

Instituto Federal Farroupilha, Campus Alegrete, Alegrete, RS, Brasil Email:tadeu.t@hotmail.com

Participação do autor: trabalhou na concepção do artigo, revisão bibliográfica, análise e interpretação dos dados e redação do artigo;

\section{Thiago Boeno Patricio Luiz}

Universidade Federal de Santa Maria, Campus de Santa Maria, RS, Brasil

Email: thiagoboeno@hotmail.com

Participação do autor: trabalhou na concepção e elaboração técnica da metodologia, do trabalho de geoprocessamento e confecção dos mapas, da análise e interpretação dos dados e da redação do texto; 